Aparici Martí, J. (2021). Esa asombrosa calle y sus numerosos recursos didácticos para la historia. Revista Electrónica Interuniversitaria de Formación del Profesorado, 24(1), 163-174.

DOI: https://doi.org/10.6018/reifop.401921

\title{
Esa asombrosa calle y sus numerosos recursos didácticos para la historia
}

Joaquín Aparici Martí

Departament de Pedagogia (Didàctica de les Ciències Socials). Universitat Jaume I. Castelló

\section{Resumen}

La calle está a nuestro alcance, llena de recursos didácticos para el proceso de enseñanza y aprendizaje de la historia, del patrimonio, de la cultura, de las matemáticas, de la lengua, etc. $Y$ muchos de ellos pasan desapercibidos. Utilicemos los recursos que la calle nos ofrece para motivar al alumnado, para que se implique en las labores de descubrimiento, de interpretación, de síntesis, etc. y se sienta parte integrante en el proceso de la elaboración del posterior discurso informativo.

\section{Palabras clave}

Didáctica; descubrir; historia; calle.

\section{That amazing street and its countless didactic resources for the history}

\begin{abstract}
The street is within our reach full of didactic resources for the teaching and learning of the historical process, the heritage, the culture, the mathematics, the language, etc. But, unfortunately, they usually go unnoticed. We use these resources with the pupils to motivate them and involve them in the discovery, interpretation and synthesis tasks. Finally, the pupils become an integral part of this process of writing.
\end{abstract}

\section{Key words}

Didactics; to discover; history; street.

\section{Contacto:}

Joaquín Aparici Martí - japarici@uji.es 


\section{Introducción}

Desde la infancia, y tras nuestra propia vivienda, la calle es uno de los principales escenarios donde se inicia el proceso de socialización del individuo. En esa calle, espacio lúdico para los más pequeños, se puede observar el contacto intergeneracional e intercultural de forma diaria. Imagen cotidiana es ver a los abuelos y abuelas paseando con los nietos y nietas por las aceras, llegando al parque. También es usual observar a esos pequeños jugando e interactuando con otros pequeños de orígenes geográficos y manifestaciones culturales diversas. Pero además, esa calle es a su vez un ámbito donde aprender elementales normas de convivencia y respeto (como por ejemplo el cuidado del entorno). Y como no, también es un ámbito de preservación de la memoria (placas conmemorativas, estatuas, edificios, ...). La calle está presente en nuestra vida y, por tanto, en nuestro contínuo proceso de aprendizaje, tengamos la edad que tengamos. En definitiva ese espacio próximo contiene una increible fuente de recursos didácticos. En el ámbito de la historia, estos son a su vez parte importante del legado patrimonial del pasado que ha llegado a nuestros días. La calle formaría parte de un museo abierto sobre el que el individuo aboca su propia percepción, abierto a todas horas y al alcance de todos (Juanola, 1989; Huerta, 2006). La conservación de sus elementos patrimoniales, su adecuada gestión y la difusión de su conocimiento pueden resultar activos poderosos para el proceso de enseñanza-aprendizaje. La ciudad (entiéndase ahora por calle) permite el análisis de numerosos elementos visuales urbanos que nos permite mirarlos al tiempo que también nosotros somos observados por los responsables de llenar la ciudad de esos mensajes visuales. Esas calles son punto de convergencia de contextos, de estilos de vida y de herencias culturales. La ciudad y sus calles no son ajenas a la acción educativa (Huerta, 2015).

\section{Marco teórico}

Partiendo desde esas bases, y en relación con la didáctica de las Ciencias Sociales, se pueden plantear muchos contenidos para trabajar espacios próximos como la calle, el barrio o la localidad, con niños y niñas de infantil o de primaria, pero también podemos hacerlo con los alumnos de educación secundaria y bachillerato. Sólo debemos adecuar los recursos existentes a las necesidades de aprendizaje de acuerdo a la madurez de los alumnos. En los libros de texto de estos niveles las propuestas relativas a los espacios históricos y su evolución, generales, ofrecen ejemplos ilustrativos a la vez que lejanos. La pretensión ahora es mostrar que podemos trabajar el entorno histórico que se menciona en muchos de esos libros, sus características y evolución, pero in situ, saliendo simplemente a observar, aplicar la teoría, y descubrir lo que muchas localidades, en sus barrios antiguos, con sus callejas estrechas y retorcidas, con la evolución de sus planos, pueden mostrar para el proceso de enseñanza-aprendizaje. Ese espacio lejano descrito en los libros de texto puede estar al alcance de una simple salida (programada dentro de una sesión) del centro educativo. Su propia ciudad, su propio barrio o calle, donde se encuentran los puntos de referencia, donde han compartido sus vivencias cuando eran más niños, donde recuerdan todos los rincones y recovecos de las callejas, puede ahora servir para, dotándolo de la pátina de la historia, ofrecer un conocimiento accesible y reconocible, asimilable y duradero, entendible a la vez que comprendido.

Si la ciudad es un espacio polivalente, un producto social resultado de procesos históricos que han dejado su huella en el paisaje urbano (Tatjer y Fernández, 2005), la calle simplemente es una parte inclusiva de ese mismo espacio. Y ello va más allá de la imagen de patrimonio que se ciñe únicamente a elementos destacables como monumentos emblemáticos o museos, puesto que la calle muestra los vivido por las generaciones pasadas y las vivencias propias de nuestra actividad que, a su vez, dejaremos para el futuro 
(Cuenca y Martín, 2009). La calle es pues un espacio cotidiano destinado a la práctica, la exploración y a la interacción con los elementos que lo configuran. En la infancia, la calle se convierte en un espacio para descubrir, guiado o no por los adultos. Es ahí donde los niños y niñas proyectan su yo hacia el entorno, donde se producen las comparaciones con los iguales, donde se reconocen las fortalezas y debilidades como miembro de un grupo (Miralles y Molina 2011). Pero la calle también supone un paso adelante en la conquista de un espacio cada vez más complejo y alejado de su propio cuerpo. La calle es el escenario donde se produce el equilibrio o desequilibrio entre naturaleza e intervención humana. Pero también es un ámbito privilegiado donde se preserva la memoria de la comunidad a través de las fiestas, los monumentos, las placas conmemorativas, el nombre de las calles, etc... (Reyes, 2011). La calle, con sus diversos elementos, comporta así una cierta democratización de la cultura a la vez que permite ampliar y diversificar el concepto de patrimonio (Besolí, 2002). Y este espacio enlaza una serie de estrategias metodológicas que permitirán innovar en la enseñanza-aprendizaje de la historia y en el descubrimiento del patrimonio histórico-cultural cercano: proximidad al elemento histórico, fomento de las relaciones y asociaciones, experiencias y vivencias, recursos y materiales motivadores y cercanos. Reivindicamos así la potencialidad didáctica del patrimonio local, próximo a la vez que infrautilizado (Miralles y Rivero, 2012).

Posiblemente, si seguimos esa dinámica, podremos conseguir elevar el espacio cotidiano donde se convive diariamente a la categoría de un espacio educador, de un museo para todos. La calle tiene su historia, y en ocasiones la muestra, aunque normalmente suele pasar desapercibida. Podemos observar la estructuración y usos del suelo, la tipología de edificios, la evolución y el cambio en los mismos, la forma de las calles, la convivencia de sus gentes, etc... Y ello sin haber tenido que desplazarse muy lejos. Además reconocer el espacio debe ir acompañado de la conceptualización de sus componentes, de los elementos que lo caracterizan, es decir, de la utilización de un vocabulario que desarrolle conceptos claros y entendibles por los alumnos. Tenemos la calle o el barrio al alcance. Ahora bien, la calle como objeto de análisis y estudio reivindicativo de las potencialidades educativas que ofrece, muestra perspectivas diferentes según el punto de incidencia sobre el que pivota la investigación, si bien todas ellas permiten la revitalización del espacio calle como argumento en los procesos de enseñanza-aprendizaje. En ocasiones se pueden diseñar unidades didácticas de educación patrimonial con diseño de sensibilización (Fontal, 2007). También se han elaborado propuestas que muestran la evolución histórica de las calles y los núcleos poblacionales en la larga duración desde la prehistoria hasta la actualidad, atendiendo al proceso de cambio constante y remodelación espacial acorde a las necesidades de la sociedad que ocupaba ese mismo espacio (Santolaria, 2014). Muy interesante es también la adecuación didáctica del entorno urbano como recurso para el aprendizaje y socialización de alumnos con transtornos del espectro autista, mostrando actividades que permiten, en el contexto de la calle, la aproximación al tiempo cronológico (lo antiguo y lo nuevo), al espacio vivido que permite la creación de mapas cognitivos referenciales (los lugares de mi pueblo, cómo llego al colegio, ...) así como una agenda visual que permita a estos alumnos desenvolverse en sus desplazamientos y afinazar su competencia y autonomía personal (Benítez y Carrasco, 2011). También se ha hecho hincapié en la dimensión pedagógica de la ciudad, y por tanto de sus calles, para desarrollar ciudadanos competentes y eficaces que puedan descifrar los códigos de la ciudad y favorecer la comprensión de las causas estructurales de los problemas urbanos, así como las políticas locales que favorezcan el camino de la igualdad y el acceso de todos los ciudadanos a los diversos referentes educativos y culturales (Alderoqui, 2006). También se puede centrar el planteamiento en propuestas histórico-artísticas que han permitido crear rutas urbanas que reactivan el aprendizaje y el redescubrimento de la ciudad y de sus calles 
por parte de un público en edad escolar, pero también por parte de los propios docentes, sacando el aula a la ciudad y mostrando esa ciudad a todos, como por ejemplo se ha hecho en Madrid, Zaragoza o Granada (Reyes, 2009; Huerta, 2014; Cambil, 2015). Incluso se puede crear una ruta artística relacionada con determinados aspectos, tipologías o mensajes mostrados a través del los graffitis callejeros, caso de Granada (Pérez, 2017). O aprovechar ese espacio público como entidad "museable" a través de otros elementos escritos y los valores culturales que pueden llegar a transmitir las letras, las caligrafías y las tipografías (Huerta, 2013 y 2015). Pero si el espacio que pretendemos estudiar ya no es visible porque el paso del tiempo ha desdibujado sus huellas, podemos entonces realizar otras actividades complementarias para poder conocerlo. Por ejemplo con el relato mediante documentos históricos de cómo era la vida en la calle un día de mercado, un día de fiesta, un día de luto, etc... en un período como la edad media (Borja, 2017). Y es que la lectura de textos y el estudio de los restos arqueológicos permiten documentar ampliamente ese pasado. Precisamente con esas informaciones podemos pasar del propio relato a la simulación o la recreación de los espacios urbanos realizando su proyección en pantalla digital desde la información que se va suministrando y según para la época que se quiera estudiar (diferentes usos del suelo, tipos de edificación, tipología del plano, espacios naturales y accidentes geográficos, avenidas y calles, estación de tren o autobús, barriadas marginales, etc.) aprovechando para ello las nuevas tecnologías informáticas y de la imagen (Sandoya, 2016).

Aún así todavía podríamos encontrarnos con situaciones manifestadas por el público en edad escolar, con expresiones como "qué aburrido" o "vaya rollo". Estas son sólo un par de las más variadas y reconocibles, y que con frecuencia suele utilizar el alumnado, generalmente de educación secundaria y bachillerato, para definir la asignatura de historia. Nombres de monarcas o emperatrices, fechas de batallas o reinados, etc... forman parte de las imágenes mentales preconcebidas que se han formado estos alumnos ante tal asignatura. Es desgraciadamente el estereotipo tradicional que proviene del modelo escolar. Pero ahora no se trata de clases de historia, sino de descubrir la historia. El objetivo propuesto por el profesor es muy claro: conseguir que les apasione la historia. Si el profesor consigue transmitir su propia pasión por esta disciplina, si es capaz de crear una cadena de engranaje que permita que su pasión llegue progresivamente al alumnado, éstos verán la historia desde otra perspectiva (Corral, García y Navarro, 2006). Y la mejor forma de apasionarlos no es impartir clase de historia, sino conseguir que ellos mismos descubran cómo es la historia, cómo funcionan las técnicas para su conocimiento, siendo a su vez partícipes en la búsqueda de los materiales para explicarla y en la posterior elaboración del discurso histórico. Ese proceso de descubrimiento interiorizado será la base de contagio de la pasión. La sensación vivida, lo emocionante del trabajo de campo, formar parte del mismo, etc... son algunas de las realidades expresadas por alumnos universitarios de magisterio de Santiago de Compostela tras su propia experiencia (Huerta y Franco, 2011). En la propuesta teórica que presento para primaria, las sesiones destinadas a la historia de la calle, reitero, no tratan de ofrecer una lección magistral. Tratan de mostrar mecanismos, técnicas y recursos didácticos, siempre adaptables, para que ellos mismos puedan descubrir la historia y así reconocer el funcionamiento del pasado, abordando los temas y problemas con la máxima objetividad posible, adecuando el proceso de trabajo a la realidad de los variados elementos que ofrece la calle. Pero aún más. La historia como pasado puede quedar interconectada con el presente y con el futuro no muy lejano mediante la vinculación de los hechos históricos con las cuestiones socialmente vivas que podemos observar en nuestra actualidad cotidiana.

En ese sentido hace ya algunos años participé en un grupo de investigación con un cometido parecido como fue la catalogación de las llamadas "capelles ceràmiques de 
carrer", es decir, paneles cerámicos devocionales que aparecen en numerosas calles. Ante la desaparición de algunos de esos paneles (por obras en las viviendas pero también por sustracción y robo), o ante el deterioro de algunos (provocado por comportamientos incívicos como la rotura por pedradas o por la desidida de los propietarios), a cada uno de los miembros del grupo de investigación se nos asignó una o varias localidades con el fin de catalogar los paneles (fotografía, medidas, breve historia oral, ...). Con el trabajo se pretendía, inicialmente, crear un recurso didáctico de carácter patrimonial, con mapas guía de localización y pequeñas historias referentes a cada uno de los paneles que pudiera servir al público en general. Sin embargo al final el resultado resultó muy "erudito" y la cadena de transmisión del recurso quedó en el ámbito universitario sin llegar plenamente al resto de niveles educativos (Feliu et al, 2007). Esa es una de las razones por las que me atrevo a presentar la siguiente propuesta didáctica.

\section{Una propuesta didáctica}

Hagamos pues que los alumnos sean descubridores de la historia. Y para ello, utilicemos un recurso sin coste como es la propia calle. Conseguiremos que lleguen a percibir la pasión que implica escrutar el pasado y por tanto ser partícipes en su conocimiento, aportando sus propios descubrimientos y valoraciones. Obviamente esto hay que hacerlo de acuerdo al nivel educativo en el que nos encontramos (alumnos de infantil, primaria, secundaria, universitarios, etc.), y también adecuando las técnicas y el desarrollo del trabajo de campo a los elementos que cada calle nos va a ofrecer. Los especialistas en historia, arqueólogos y documentalistas fundamentalmente, tienen la labor de encontrar las fuentes e interpretarlas, como ya hemos indicado. Descubrir yacimientos o transcribir pergaminos queda por tanto fuera de la pretensión de estas líneas. Pero también es cierto que en la calle encontraremos recursos muy próximos para que los alumnos puedan comenzar a trabajar y sentirse como verdaderos investigadores. Sin darse cuenta estarían asimilando conceptos como hipótesis, búsqueda, comparación, contrastación, conclusiones, etc... Y paralelamente estarían desarrollando una actitud crítica y de respeto por los elementos del paisaje urbano que nos envuelven y que son fuente de informaciones para desarrollar el trabajo del historiador. Esas actitudes de respeto hacia el patrimonio cultural se suman al aprendizaje de los conceptos y los procedimientos.

En el modelo de propuesta que presento he escogido el entorno inmediato del CEIP L'Assumpció (sito en Vall d'Uixó, Castelló), donde he podido catalogar hasta 67 posibles elementos que permitan al alumnado descubrir historia (arquitecturas, pinturas, esculturas, iconografías, textos escritos, volúmenes y formas, placas identificativas, etc...). Dichos elementos se encuentran diseminados en las calles adyacentes al centro educativo. Los alumnos pasan diariamente ante esos elementos y en pocas ocasiones se detienen a observarlos o preguntar qué son, qué significado tienen o por qué están ahí. La propuesta es utilizar ese catálogo de fotografías digitales para que los alumnos puedan descubrir y así ser partícipes del proceso de enseñanza-aprendizaje. Descubrirán, investigarán y podrán mostrar sus resultados. Además, ciertos aspectos de la búsqueda y comparación con elementos del pasado permitirán establecer la conexión existente con la actualidad. En ese sentido debemos tener presente que la propuesta es adaptable a la realidad de cada centro y que los elementos culturales o patrimoniales pueden ser relativamente diferentes según la zona de estudio o prospección.

Ahí podemos engarzar una segunda fase de la propuesta (actualmente en discusión) que supondría establecer contacto con el resto de centro educativos de la localidad presentándoles el modelo teórico de trabajo para que éstos, en su área próxima, puedan ofrecer al alumnado la posibilidad de descubrir toda la serie de recursos accesibles a la vez 
que diferentes a los que tienen otros centros. Aunando esfuerzos, el trabajo en común de todos los centros podría ofrecer un completo catálogo de recursos más allá del área de proximidad, englobando al conjunto de barrios y, por tanto, al municipio. Ese catálogo que podremos considerar como un recurso didáctico elaborado por la puesta en común entre alumnado, profesorado, escuela, barrio y municipio, será el resultado de la localización de todos aquellos aspectos patrimoniales y culturales que puedan servir para trabajar y descubrir la historia desde la propia calle, retroalimentándose. Además, en una fase ulterior se podrá crear un plano o mapa de localización de los mismos.

Así pues, la propuesta teórica presentada permitiría trabajar los siguientes tipos de contenidos, a saber conceptuales (hipótesis, comparación, contrastación, síntesis, conclusión); procedimentales (hipotetizar, buscar informaciones y contrastarlas, fotografíar, sintetizar, establecer conclusiones); y actitudinales (respeto por todos los elementos que nos rodean y que son fuente de información. $Y$ en relación a la historia respeto por el patrimonio cultural). En el caso que ahora se presenta, ese proceso de aprendizaje sobre la calle puede iniciarse, por ejemplo, con la propuesta de varias actividades interrelacionadas:

\section{a) De lo antiguo a lo actual}

El profesor puede presentar al conjunto de la clase una imagen previamente obtenida a través de un buscador de internet (imagen 1). Dicha imagen muestra ciertos elementos históricos o culturales de un pasado alejado pero cuyas formas resultan muy similares a las que podemos encontrar en ciertos elementos de nuestra calle. Se programa una salida durante la cual se pide al alumnado que trate de localizar en esas calles próximas al centro educativo determinados elementos susceptibles de ser considerados como patrimoniales e históricos (bajo orientación del profesorado) y que tengan significativas similitudes con aquella imagen previamente mostrada. El alumnado, cámara en mano, fotografía esos elementos localizados que dan inicio a la configuración de un dossier o catálogo (imagen 2). Fotografiar el entorno próximo ayudará a entender mejor el paisaje al que estamos habituados, creando ciertas afinidades respecto a estímulos en los que no habíamos reparado anteriormente (Huerta, 2006). Descargada cada una de esas imágenes en el ordenador, a continuación se procede a la descripción lo más detallada posible de aquella (ubicación, datación, etc...), creándose una ficha compleja (imagen y datos). Después se puede pedir al almunado que establezca comparaciones entre lo que ha localizado en la calle y aquello otro que proviene de ese pasado más lejano. Para ello se procederá a la búsqueda de resultados a través de internet, lo que permitirá pautar el trabajo con el ordenador, supervisando la forma de preparar las cuestiones para obtener resultados; establecer elementos de discriminación o selección de informaciones y fuentes; analizar éstas y ser capaz de sintetizarlas para dar respuestas coherentes, etc... Para ayudar a establecer la comparación entre imágenes se podría proponer una pequeña batería de preguntas orientativas que puede ser ampliada de acuerdo al nivel del alumnado (primaria, secundaria, etc...).

- ¿Puedes describir lo que ves, con su forma, materiales, etc.?

- ¿Qué función crees que tiene, o para qué sirve?

- ¿Qué semejanzas observas entre las dos imágenes?

- ¿Y qué diferencias son más destacables?

- ¿Qué antigüedad crees que tienen?

- ¿Dónde podemos localizar el elemento mostrado en la primera imagen? 


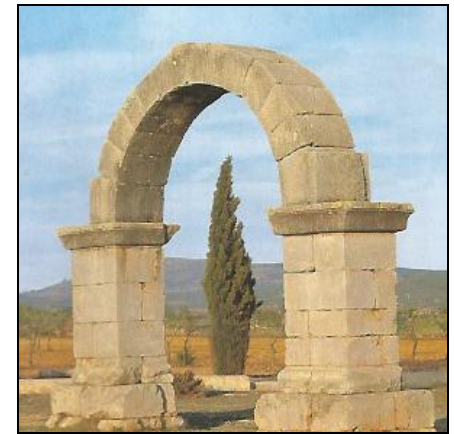

Imagen 1. Arco romano de Cabanes sobre la antigua Via Augusta. Cruce de caminos en el Pla de l'Arc (Cabanes, Plana Alta). Siglo II pC (aproximadamente).

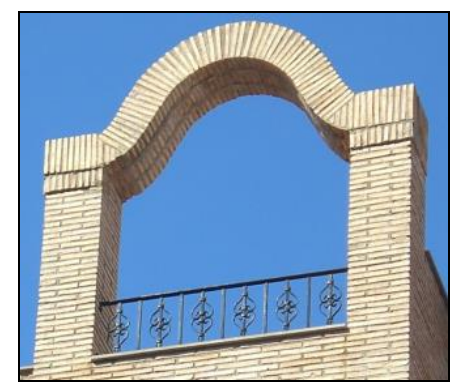

Imagen 2. Arco decorativo en la balconada de una vivienda unifamiliar. Plaça de l'esglèsia de l'Assumpció (Vall d'Uixó). Década de 1990 (aproximadamente). Fotografía: J. Aparici.

\section{b) De lo actual a lo antiguo}

Una segunda opción puede ser escoger algunas de las imágenes del dossier recogido y mostrarlas al alumnado de un curso que no haya participado en la salida. En primera instancia, y con una nueva salida programada, este grupo de alumnos tratará de localizar las imágenes captadas por sus compañeros en la calle (imágenes 3, 4, 5). Una vez se muestre su ubicación, el profesor podrá proceder a su descripción detallada mediante las fichas explicativas que habrían sido creadas por parte del alumnado que sí había salido a efectuar la catalogación y los dossieres. A diferencia de la actividad anterior en la que el docente entregaba una primera imagen para comparar, ahora, de regreso al aula, se propone al alumnado la búsqueda de imágenes similares o lo más parecidas posibles a través de un buscador de internet (ya no las facilita el docente), siendo imágenes procedentes de pinturas, esculturas, arquitecturas, etc. que pueden, tal vez, haber influido en las primeras. Localizadas éstas, se guardarán en un archivo diferente y se procederá a documentar por escrito sus características para tratar de trazar la posible influencia de unas sobre las otras, comparándolas. Como posible ejemplo de trabajo se muestran tres caras de agua en canaladuras. Los alumnos deberán buscar en internet y tratar de identificar las similitudes que presentan estas caras con una divinidad griega, un querubín y un hombre medieval. 

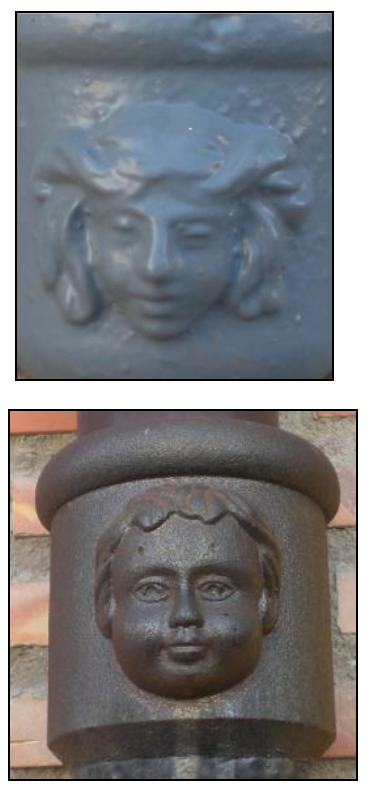

Imágenes 3, 4 y 5. Caras de agua en canaladuras. Calles Lope de Vega, Escultor Marco y Plaça l'Assumpció (La Vall d'Uixó). Fotografía: J. Aparici.

En esta misma actividad se puede incluir una breve aproximación transversal al sistema comunicativo no textual basado en imágenes o iconos publicitarios (que muestran un significado supuestamente conocido por el conjunto de la sociedad que los utiliza). Estos dibujos y representaciones hacen referencia a una tipología específica de negocio y se ubican en la zona superior de la entrada al local. Tras una breve explicación del docente, la inclusión de esas imágenes icónicas en el dossier permitirá establecer nuevamente la conexión con el pasado y observar cómo antiguamente también determinados oficios y negocios situaban en el acceso a sus locales símbolos distintivos y representativos, sin necesidad de un mensaje escrito. Al igual que antes, podemos plantear al alumnado la identificación del significado de la simbología actual del dibujo o icono y sugerir la búsqueda en internet de elementos similares del pasado para establecer comparaciones. 


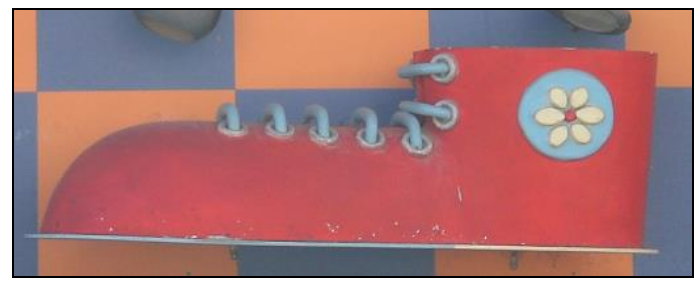

Imagen 6. Escultura de un zapato de grandes dimensiones. Avenida Corazón de Jesús (Vall d'Uixó). Fotografía: J. Aparici.

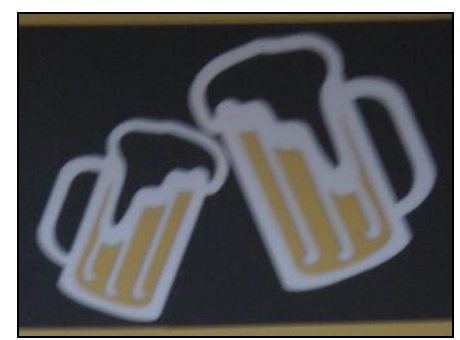

Imagen 7. Panel con jarras de cerveza. Avenida Octavi Ten (Vall d'Uixó). Fotografía: J. Aparici.

\section{c) El nombre de las calles}

Las personas habitamos en una vivienda situada en una calle, avenida, plaza, etc... Son muchas las ocasiones en que se precisa dar la dirección postal para poder ser localizados, por ejemplo, para la recepción de cualquier paquete postal o notificación administrativa. Cada vivienda en una calle está identificada por una numeración y en ocasiones una letra. $Y$ cada calle presenta a su vez un nomenclátor que facilita la localización. Hay barrios donde el sistema busca cierta simplificación, ofreciendo dos coordenadas (eje de abcisas y ordenadas). Por ejemplo, las viviendas del barrio Carbonaire están organizadas según la travesía X, número Y; o el Grupo La Unión, cuyo plano queda organizado según la manzana $X$, número $Y$ (ambos barrios situados en Vall d'Uixó). Sin embargo, aquello más frecuente es que cada calle tenga un nombre propio, nombre que obedece a unas determinadas circunstancias que favorecieron su denominación como tal. De hecho, que una calle sea denominada Carrer de l'Abeurador tácitamente implica una información muy valiosa sobre un referente que tal vez ya no sea visible en la actualidad, pero que en tiempo pasado sí existió. $O$ se puede analizar el impacto que supuso la actividad antrópica sobre el espacio urbano y cómo este pudo determinar la nomenclatura de ciertas calles, como por ejemplo en València la calle Caballeros o el barrio Velluters, nombres que obedecen a cierto estatus socio-profesional de sus habitantes existente en la edad media. Inluso cabe la posibilidad de ahondar a través de cierto enfoque (no exento de polémicas) que liga los posibles cambios de nombres de las calles como reflejo de los cambios en el poder político local o también nacional (Ordinas y Binimelis, 2018).

Así pues, podemos aprovechar esta situación para poner en práctica, nuevamente, el proceso de indagación y descubrimiento de la historia. Por un lado, cámara en mano, el alumnado puede obtener imágenes de las placas identificativas y crear un dossier. $\mathrm{Y}$ a 
través de éste podemos preparar una nueva batería de preguntas a resolver, algunas de las cuales precisarán nuevamente del uso de un buscador en internet. Además, esta actividad cuenta con el aliciente de efectuar posibles encuestas orales a las personas más veteranas que habitan en tal lugar, con la capacidad de grabación de las respuestas a preguntas variadas relativas al nombre de la calle o el barrio (si saben el por qué tiene ese nombre o si queda alguna reminiscencia visible que permita establecer la conexión entre el nombre y lo que le da nombre), e inclusive ampliar el espectro de la documentación con preguntas a esas mismas personas sobre su propia experiencia vital en el lugar (tipo de trabajo que desarrollaban, origen geográfico, antiguas fiestas o costumbres en la calle, etc...).

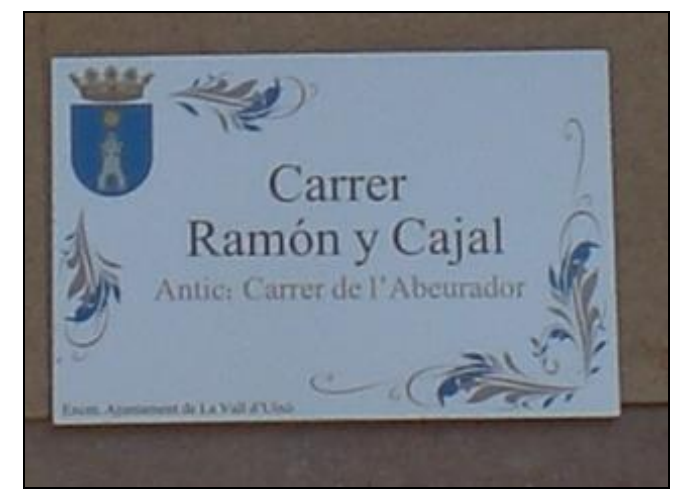

Imagen 8. Placa indicativa de nombre de calle. Fotografía: J. Aparici.

Nuevamente, una posible batería de preguntas puede ayudar al inicio de la recopilación documental:

- ¿Quién da nombre a la calle?

- ¿Era una persona famosa? ¿Por qué motivo?

- ¿Antiguamente la calle tenía otro nombre? ¿Qué podía indicar?

- ¿Podemos encontrar en la calle algún elemento relacionado con el nombre actual o con el antiguo?

- ¿Conoces otras calles que hayan cambiado de nombre? ¿Se indica el cambio en la placa? ¿Cómo has averiguado que ha cambiado de nombre?

\section{Conclusión}

A través de este ejemplo teórico, la idea es reivindicar el hecho de que la calle está al alcance de todos, que hay numerosos recursos para trabajar transversalmente aspectos como las matemáticas, la lengua, la historia, etc... Esa calle puede ser un gran museo al aire libre. Sin embargo, muchos de esos posibles recursos pasan desapercibidos. La proximidad de la calle o el barrio a la vida cotidiana del alumnado permite interiorizar mejor las ideas o los conceptos trabajados además de facilitar que ellos mismos sean partícipes del descubrimiento. El alumno es el verdadero protagonista del proceso de aprendizaje, desarrollando toda una serie de habilidades de descubrimiento que servirán para su 
formación futura. Una de ellas es la participación activa en el proceso a través de la fotografía digitalizada y la creación de dossieres, algunos procedentes de la encuesta oral y otros con informaciones localizadas mediante un buscador de internet, aspecto este último que permitirá a su vez trabajar la competencia en las nuevas tecnologías. La creación de esos dossieres se podría complementar ulteriormente con la realización de un plano o mapa de localización de los elementos indicados. Incluso aquella comparación con imágenes del pasado podría permitir la observación de ciertas pervivencias e influencias sobre nuestro presente y favorecer la toma de conciencia sobre el respeto, la conservación y transmisión del patrimonio cultural. Como marco teórico de la propuesta, ese proceso de enseñanzaaprendizaje posiblemente resulte significativo a la vez que emotivo, por cuanto se trabaja con lo cercano y conocido. Y para ello sólo tenemos que salir de clase y aprovechar ese fantástico recurso didáctico.

\section{Referencias}

Alderoqui, S. S. (2006). La ciudad: un territorio que educa. Caderno CHR, 16 (38), 153-176.

Benítez, M., y Carrasco, L. (2011). El entorno urbano como recurso didáctico para el aprendizaje de la autonomía, socialización y comunicación del alumnado TEA. Escuela Abierta, (14), 125-148.

Besolí, A. (2002). L'ús de les tecnologies audiovisuals com a recurs didàctic en museus d'història i espais de presentació del patrimoni. Temps d'Educació, (26), 99-115.

Borja, H.J. (2017). La calle, escenario medieval. Boletín del Instituto de Cultura del Alto Palancia, (24), 67-81.

Cambil, M. de la E. (2015). La ciudad como recurso para la enseñanza aprendizaje del patrimonio cultural. Opción, 31 (3), 295-319.

Corral, J.L., García, C., y Navarro, G. (2006). Taller de historia. El oficio que amamos. Barcelona, España: Edhasa.

Cuenca, J.M., y Martín, M. (2009). La ciudad actual a través de la ciudad histórica. Cuadernos de Pedagogía, (394), 67-69.

Feliu, J., Ortells, V., Verdegal, J., Soriano, J., Aparici, J., Benaches, C., y Pons, R. (2007). Historia del retablo cerámico en la Plana de Castelló. Análisis de un recurso patrimonial. Castelló, España: Fundación Dávalos-Flétcher.

Fontal, O. (2007). El patrimonio cultural del entorno próximo: un diseño de sensibilización para secundaria. Enseñanza de las Ciencias Sociales. Investigación didáctica, (6), 31-47.

Huerta, R. (2006). La ciudad escrita, museo cotidiano. Aula de Innovación Educativa, (151), 35-38.

Huerta, R. (2013). Docentes paseando por las letras de la ciudad. Arteterapia: Papeles de arteterapia y educación artística para la inclusión social, (8), 123-136.

Huerta, R. (2014). Los sitios de Zaragoza. Rutas urbanas para educar desde la ciudad. Revista América Patrimonio, (8), 102-119. 
Huerta, R. (2015). Optimizant el diàleg necessari entre ciutat, museu i educació artística. Temps d'Educació, (49), 309-312.

Huerta, R., y Franco, C. (2011). Público y privado. Espacios urbanos observados por el alumnado de magisterio. Íber. Didáctica de las Ciencias Sociales, Geografía e Historia, (69), 102-111.

Juanola, R. (1989). La percepción del entorno, un museo abierto. Cuadernos de Pedagogía, (167), 29-31.

Miralles, P., y Molina, S. (2011). Didáctica de las CCSS para el área de conocimiento del entorno. En P. Rivero (Ed.), Didáctica de las Ciencias Sociales para educación infantil, 89-110. Zaragoza, España: Mira Editores.

Miralles, P., y Rivero, P. (2012). Propuestas de innovación para la enseñanza de la historia en educación infantil. REIFOP, 15 (1), 81-90. Recuperado de http//www.aufop.com (consulta 14-06-19).

Ordinas, A., y Binimelis, J. (2018). Los nombres de lugar: un recurso didáctico en la enseñanza geográfica del paisaje natural. Anales de Geografía de la Universidad Complutense, 38 (2), 385-405.

Pérez, R. (2017). El graffiti como recurso didáctico en el ámbito educativo: el caso de Granada. UNES (Universidad, Escuela y Sociedad), (3), 64-82.

Reyes, J. L. (2009). Mi casa, mi calle, mi ciudad: experiencias sobre el espacio infantil en el Madrid histórico. Terra Plural, Ponta Grossa, 3 (1), 9-27.

Reyes, J.L. (2011). Didáctica de las ciencias sociales: vida cotidiana, conocimiento de si mismo y autonomia personal. En P. Rivero (Ed.), Didáctica de las Ciencias Sociales para educación infantil, 65-88. Zaragoza, España: Mira Editores.

Sandoya, M.A. (2016). Reportajes fotográficos de tu barrio. Enseñar Ciencias Sociales. 35 actividades para desarrollar capacidades, Ed. UOC, 240-241.

Santolaria, A. (2014). La ciudad como recurso didáctico. Edetania, (45), 235-244.

Tatjer, M., y Fernández, M. (2005). La ciudad como taller. Iber. Didáctica de las Ciencias Sociales, Geografía e Historia, (43), 58-66. 